\title{
In vitro and ex vivo effect of hyaluronic acid on erythrocyte flow properties
}

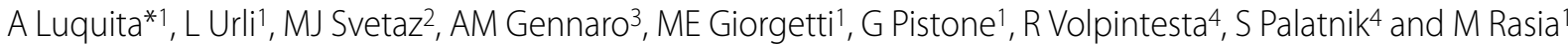

\begin{abstract}
Background: Hyaluronic acid $(\mathrm{HA})$ is present in many tissues; its presence in serum may be related to certain inflammatory conditions, tissue damage, sepsis, liver malfunction and some malignancies. In the present work, our goal was to investigate the significance of hyaluronic acid effect on erythrocyte flow properties. Therefore we performed in vitro experiments incubating red blood cells (RBCs) with several HA concentrations. Afterwards, in order to corroborate the pathophysiological significance of the results obtained, we replicated the in vitro experiment with ex vivo RBCs from diagnosed rheumatoid arthritis (RA) patients, a serum HA-increasing pathology.
\end{abstract}

Methods: Erythrocyte deformability (by filtration through nucleopore membranes) and erythrocyte aggregability (EA) were tested on blood from healthy donors additioned with purified HA. EA was measured by transmitted light and analyzed with a mathematical model yielding two parameters, the aggregation rate and the size of the aggregates. Conformational changes of cytoskeleton proteins were estimated by electron paramagnetic resonance spectroscopy (EPR).

Results: In vitro, erythrocytes treated with HA showed increased rigidity index (RI) and reduced aggregability, situation strongly related to the rigidization of the membrane cytoskeleton triggered by $\mathrm{HA}$, as shown by EPR results. Also, a significant correlation ( $r: 0.77, p<0.00001$ ) was found between Rl and serum HA in RA patients.

Conclusions: Our results lead us to postulate the hypothesis that HA interacts with the erythrocyte surface leading to modifications in erythrocyte rheological and flow properties, both ex vivo and in vitro.

\section{Background}

Elevated seric hyaluronic acid (HA) is a feature of certain inflammatory conditions, notably rheumatoid arthritis and scleroderma, and also accompanies tissue damage, sepsis, liver malfunction and some malignancies [1-8].

Additionally, the employment of HA is currently suggested in the therapy of arthritis, arthrosis, psoriasis, and it is also included in treatments with cosmetic products [9$12]$.

Being HA a macromolecule present in plasma, it could interact with the red blood cell (RBC) surface, as it happens with albumin. In a previous work [13] we have demonstrated that albumin adsorption impairs erythrocyte rheology in a concentration-dependent fashion increasing the erythrocyte rigidity index (RI). Such facts lead us to hypothesize that the reduction in erythrocyte deformability

* Correspondence: luquitale@hotmail.com

1 Cátedra de Física Biológica, Facultad de Ciencias Médicas, Universidad

Nacional de Rosario, Santa Fe 3100, 2000 Rosario, Argentina
(RI increase) observed in serum HA-increasing pathologies, could be due to HA interaction with RBC surface which contributes to the impaired flow properties observed in these pathologies $[14,15]$.

We therefore conducted this study to investigate the significance of serum HA effect on erythrocyte flow properties.

We performed in vitro experiments incubating RBCs from healthy donors with several HA concentrations. Afterwards, in order to corroborate the obtained results, we selected a serum HA-increasing pathology and replicated the experiment ex vivo with RBCs from those patients. We chose rheumatoid arthritis RA patients because in an earlier paper we demonstrated a reduction in erythrocyte RI that is in close correlation with the Disease Activity Score (DAS 28-4) index during the clinical remission of the process [16]. 


\section{Methods}

The Ethics Committee of the Facultad de Ciencias Médicas, Universidad Nacional de Rosario, Argentina approved the study protocol, and all participants signed an informed consent according to the recommendations of the Declaration of Helsinki [17].

\section{Blood sample collection and laboratory assays}

Blood samples of RA patients were obtained by venipuncture and separated in 2 aliquots. One of them was collected in tubes containing EDTA and assigned to determine haematimetric indexes, plasmatic protein concentration and rheological parameters. The other was collected in a dry tube and centrifuged $5 \mathrm{~min}$ at $5000 \mathrm{RPM}$ in order to obtain serum for the serum concentration of HA.

a) Haematimetric indexes: Erythrocyte count was assessed by a hæmocytometer and hæmoglobin by the cyanmetahæmoglobin method. From these values, MCV and $\mathrm{MCHC}$ were calculated.

b) Plasmatic immunoglobulin concentration: by radial immunodiffusion.

c) Fibrinogen concentration: by commercial kinetic test kit (Boehringer Mannheim, Germany).

d) $H A$ assay: by an ELISA commercial test kit (CHUGAI quantitative test Kit), using HABP (HA Binding Protein) as capture molecule [18].

\section{Haemorheological assays a) Rigidity index (RI)}

Whole blood from RA patients was centrifuged at 5000 RPM for 5 minutes, plasma and buffy coat were separated and the erythrocytes were washed twice with PBS (0.12 M $\mathrm{NaCl}, 0.03 \mathrm{M} \mathrm{H}_{2} \mathrm{KPO}_{4} / \mathrm{HNa}_{2} \mathrm{PO}_{4}$ with $2 \mathrm{mg} / \mathrm{ml}$ glucose).

Washed RBCs were resuspended (10\% hæmatocrit) in PBS with bovine albumin (0.25\%) (Sigma Chemical Co., St.Louis, MO, USA) in order to prevent erythrocyte aggregation.

Erythrocyte filtration was performed in a computerized instrument using the Reid et al. technique [19]. Briefly, a $10 \%$ suspension of washed erythrocytes was passed through a polycarbonate filter, $5 \mu \mathrm{m}$ pore size (Nucleopore Corp. USA), using a negative filtration pressure of $10 \mathrm{~cm}$ $\mathrm{H}_{2} \mathrm{O}$. The flow time required for $1 \mathrm{ml}$ of $\mathrm{RBC}$ suspension to pass through the filter was measured. Results were expressed as the rigidity index (RI) that is an estimation of erythrocyte rigidity (inverse of erythrocyte deformability) [20], defined as:

$$
\mathrm{RI}=(\mathrm{Tb}-\mathrm{Ts}) /(\mathrm{Ts}) \times 100 / \mathrm{Htc}
$$

Where: Tb: time of passage of the cell suspension through the filter; Ts: time of passage of an equal volume of PBS; Htc: hæmatocrit (10\%).
The erythrocyte deformability measurements are in accordance to the International Committee for Standardization in Haematology [21].

\section{b) Erythrocyte aggregation}

This parameter was measured in whole blood at native hæmatocrit. An instrument [22] assembled as a model designed by Tomita et al. [23] was used. In brief, it consists of a densitometer head that detects light transmission changes in whole blood during the aggregation process that follows a disaggregating agitation [24].

The registered data were analyzed with a mathematical model allowing us to determine two parameters: $2 \mathrm{k}_{2} \mathrm{n}_{0}$, which stands for the initial rate of the process, and $\mathrm{s}_{0} / \mathrm{n}_{0}$, which estimates aggregation intensity and average rouleaux size at process completion.

\section{c) Erythrocyte membrane fluidity}

Erythrocyte membrane fluidity was estimated by electron paramagnetic resonance spectroscopy (EPR) using liposoluble spin labels 5, 12 and 16- doxyl stearic acid (5-, 12-, and 16-SASL, Sigma Chemical Co., St. Louis, MO, USA), which sense the mobility of the acyl chains at different depths in the lipid leaflet of the RBC membrane [25]. The EPR spectra were obtained at $25 \pm 1^{\circ} \mathrm{C}$ in a Bruker ER-200 spectrometer operating at $\mathrm{X}$ band $(9800 \mathrm{MHz})$.

In the case of erythrocytes from RA patients, membrane fluidity was assessed using the parallel component of the nitrogen hyperfine tensor of 5-SASL $\left(\mathrm{T}_{/ /}\right)$as a representative parameter of lipid chain rigidity. Thus, increased $\mathrm{T}_{/ /}$ values are indicative of decreased membrane fluidity [26].

In the case of cells incubated in vitro with HA, we evaluated $\mathrm{S}_{5}, \mathrm{~S}_{12}$ and $\mathrm{S}_{16}$ order parameters at different depths of the lipid bilayer, from the spectra of 5, 12 or 16-SASL. As in the previous case, increased $S$ parameters indicate decreased membrane fluidity.

\section{HA purification}

HA was purified from other acid mucopolysaccharides by ecteola cellulose chromatography [27] and eluted with 0.05 $\mathrm{N} \mathrm{HCl}$. HA concentration in the eluate was colorimetrically determined, through estimation of the glucuronic acid content, by using carbazole in sulphuric medium [28].

The elution solution was neutralized to $\mathrm{pH} 7.4$ with 0.05 $\mathrm{N} \mathrm{NaOH}$

\section{In vitro experiments}

\section{- Erythrocyte incubation in hyaluronic acid solutions and RI} determination

Blood samples were obtained from healthy adults by venipuncture and collected in tubes containing EDTA $(1,146$ $\mathrm{mg} / \mathrm{ml}$, Sigma Chemical Co., St.Louis, MO, USA) as anticoagulant. Each sample was fractioned in 5 aliquots $(1 \mathrm{ml})$. The first sample (control; $\mathrm{n}=6$ ) was additioned with $1 \mathrm{ml}$ of neutralized elution solution and the other ones with $1 \mathrm{ml}$ of purified HA in rising concentrations, yielding the follow- 
ing final nominal concentrations $(\mu \mathrm{g} / \mathrm{ml}):\left[\mathrm{HA}_{1}\right]=50$; $\left[\mathrm{HA}_{2}\right]=87 ;\left[\mathrm{HA}_{3}\right]=109 ;\left[\mathrm{HA}_{4}\right]=190(\mathrm{n}=6)$. After 30 min incubation at $37^{\circ} \mathrm{C}$, serum $\mathrm{HA}$ concentration ([HA]s) and erythrocyte RI were determined for each sample in a similar way as for RA patients.

\section{- Reversibility of HA-erythrocyte interaction}

In order to test the reversibility of HA-erythrocyte interaction, RI was determined again in erythrocytes of each sample after washing twice with PBS.

-Aggregability determination in erythrocytes incubated in HA Blood samples were divided into two fractions; one of them was added with purified HA to reach a final concentration similar to that found in serum of RA patients, $[\mathrm{HA}]=109$ $\mu \mathrm{g} / \mathrm{ml}$ (HA group; $\mathrm{n}=15$ ), and the other one was added with the same volume of the the neutralized elution solution (control group; $\mathrm{n}=15$ ). Both aliquots were incubated for 30 min at $37^{\circ} \mathrm{C}$. Afterwards, serum concentration of HA was determined and erythrocyte aggregability was measured as described previously.

EPR spin label studies of the cytoskeleton proteins in haemoglobin-free erythrocyte membranes In order to obtain haemoglobin-free erythrocyte membranes, RBC's from regular donors were subjected to hypotonic lysis in sodium phosphate buffer $5 \mathrm{mM}, \mathrm{pH} 8$ (for $30 \mathrm{~min}$ at $4^{\circ} \mathrm{C}$ ) and the pellet was thoroughly washed [29]. The membrane samples were subdivided into two fractions. One of them (HA group; $\mathrm{n}=6$ ) was added with purified HA to reach concentrations similar to those found in serum of RA patients, and the same volume of the elution solution was added to the other fraction (control group; $\mathrm{n}=6$ ). Both media had been previously neutralized to $\mathrm{pH}$ 7.4.

Both aliquots were incubated with the spin label 4maleimido-Tempo (Mal-Tempo, Sigma Chemical Co., St.Louis, MO, USA), at a concentration of 30-50 $\mu \mathrm{g}$ per mg of protein, in the dark, at $4^{\circ} \mathrm{C}$ for $1 \mathrm{~h}$.

The protein-specific spin-label Mal-Tempo is known to bind covalently to cysteine sulfhydryl groups of cytoskeleton membrane proteins. W/S parameter, estimated from the Mal-Tempo EPR spectrum [29], reflects two types of membrane protein SH-binding sites for the spin label: strongly and weakly immobilized sites (S and $\mathrm{W}$ sites, respectively). Changes in the W/S parameter are indicative of conformational changes in the cytoskeleton proteins.

\section{Ex vivo experiments \\ -RA Patients}

One hundred female RA patients attending an outpatient service at the Departamento de Reumatologia, Universidad Nacional de Rosario, Argentina, were included in the present study (mean age $48 \pm 17 \mathrm{yr}$ ).

The patients were part of a follow-up study recruited between the years 2000 and 2003 [13]. RA diagnosis was established following the American College of Rheumatology criteria [30-32]. Patients with cardiovascular or liver disease, cancer, chronic infectious diseases, HIV positive serology or diabetes mellitus as well as heavy smokers $(>20$ cigarettes/day) and patients who were under medication that could alter hæmorheological blood properties, were dismissed. The laboratory process has been described previously [13]. The clinic activity of the disease was evaluated by means of the Disease Activity Score (DAS 28-4) [33].

\section{Controls}

The control group consisted of 40 female non-smoker healthy volunteers, age-matched (mean: $43 \pm 12 \mathrm{yr}$ ).

\section{Statistical analysis}

The Kruskal-Wallis' test was performed considering variables; RI: RI after washes; afterwards Mann-Whitney's U test was applied as post hoc one. Wilcoxon's test was performed between RI and RI after washes for each group. Data are presented as median and $95 \%$ confidence interval (Figure 1).

Comparisons for aggregation parameters $\left(2 \mathrm{k}_{2} \mathrm{n}_{0}\right.$ and $\left.\mathrm{s}_{0} \mathrm{n}_{0}\right)$ between HA and control groups were performed by Student's t-test for paired data. Values are presented as mean \pm standard deviation (Table 1).

Differences in cytoskeleton protein conformation and in lipid chain ordering at different levels of the membrane between control and HA treated erythrocytes, assesed by EPR, were analized using Wilcoxon test for paired data. Results are expressed as median and $95 \%$ confidence interval (Table 2).

The correlation between RI and [HA]s in RA patients was estimated using Pearson product-moment correlation coefficient. Values were presented as mean \pm standard deviation (Table 3).

Pearson product-moment correlation coefficient was also used to analyze the dependence of RI with $[\operatorname{IgG}],[\operatorname{IgM}]$, $\mathrm{MHCM}, \mathrm{T}_{/ /}$and fibrinogen concentration in RA patients.

\section{Results}

\section{In vitro experiments}

Figure 1 shows that the rigidity index is significantly increased after incubation with $\mathrm{HA}$ at all the measured [HA] range. There is a remarkable good correlation between RI and $[\mathrm{HA}] \mathrm{s}\left(\mathrm{r}_{\mathrm{s}}: 0.996, \mathrm{p}<0.00001\right)$. Figure 1 also shows that after two washings, RI returns to control values. Thus, it can be postulated that HA reduces erythrocyte deformability reversibly and in a concentration dependent manner.

Regarding aggregation properties, the results presented in Table 1 indicate a significant decrease in the parameter $2 \mathrm{k}_{2} \mathrm{n}_{0}$ in erythrocytes incubated with HA, while no differences in the parameter $\mathrm{s}_{0} / \mathrm{n}_{0}$ are observed. This means that the presence of HA in the incubation medium diminishes 


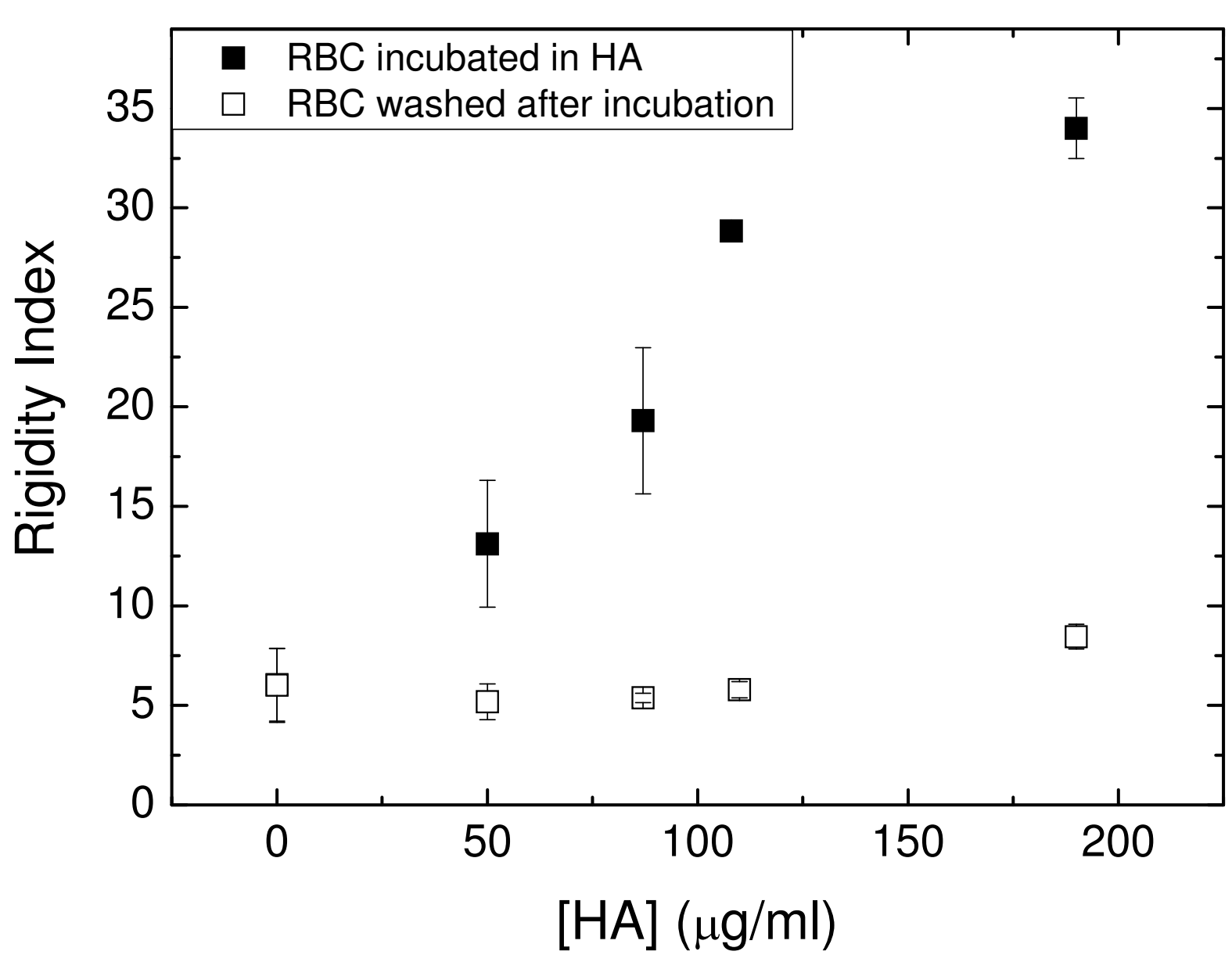

Figure 1 Rigidity Index (RI) of erythrocytes incubated in vitro with variable HA concentrations, and reversibility of HA effect. In vitro effect of several.hyaluronic acid (HA) concentrations on rigidity index (RI). Each sample was fractioned in 5 aliquots ( $1 \mathrm{ml})$. The first sample (control; $\mathrm{n}=6$ ) was additioned with $1 \mathrm{ml}$ of neutralized elution solution and the other ones with $1 \mathrm{ml}$ of purified $\mathrm{HA}$ in raising concentrations, yielding the following final nominal concentrations $(\mu \mathrm{g} / \mathrm{ml}):\left[\mathrm{HA}_{1}\right]=50 ;\left[\mathrm{HA}_{2}\right]=87 ;\left[\mathrm{HA}_{3}\right]=109 ;\left[\mathrm{HA}_{4}\right]=190(\mathrm{n}=6)$. As can be seen, after two washings, Rl returns to control values. Data: median, C.I.95\%: confidence interval. $(n=6)$. Rl: Kruskal Wallis' test: $\mathrm{H}=27.87 ; \mathrm{p}<0.0001$. Post hoc tests were performed with Mann-Whitney's $U$ between groups, $p<0.05$. Rl after wash: Kruskal Wallis' test n.s.

the erythrocyte aggregation rate, without significantly modifying the size of the aggregates.

Table 2 shows that the order parameters $\mathrm{S}$, calculated from the EPR spectra of liposoluble spin labels, do not exhibit significant differences between HA group and control group, indicating that the fluidity of the lipid bilayer is not altered as a consequence of the presence of HA. Conversely, the W/S parameter, calculated from the spectra of Mal-Tempo, was significantly diminished in the HA group. This suggests that incubation with HA introduces changes in the conformation of the cytoskeletal protein spectrin.

Table 1: Erythrocyte aggregability in the presence of HA and its control $(n=15)$

\begin{tabular}{|c|c|c|}
\hline & $2 \mathrm{k} 2 \mathrm{n} 0$ & $\mathrm{~s} 0 / \mathrm{n} 0$ \\
\hline Control & $1.98 \pm 0.14$ & $1.867 \pm 0.015$ \\
\hline HA Group & $1.29^{* *} \pm 0.21$ & $1.866 \pm 0.004$ \\
\hline
\end{tabular}

Data: mean \pm standard deviation.

Degree of significance of the difference between groups: ${ }^{* *} p<0.01$ 
Table 2: HA effect on cytoskeleton protein conformation and on lipid chain order at different levels

\begin{tabular}{ccccccc}
\hline & [HA] $\mathbf{\mu g} / \mathbf{m l}$ & W/S & S5 & S12 & S16 \\
\hline Control & $<10$ & $\begin{array}{c}3.20 \\
(3.10-3.30)\end{array}$ & $\begin{array}{c}0.693 \\
(0.685--0.703)\end{array}$ & $\begin{array}{c}0.525 \\
(0.524--0.527)\end{array}$ & $(0.228--0.230)$ \\
\hline HA Group & 103 & $\begin{array}{c}2.65^{*} \\
(100-105)\end{array}$ & $\begin{array}{c}0.690 \\
(2.60--2.70)\end{array}$ & $\begin{array}{c}0.521 \\
(0.520--0.524)\end{array}$ & $(0.225--0.233)$ \\
\hline
\end{tabular}

W/S: ratio of the spectral amplitudes of Mal-Tempo attached to strongly and weakly immobilized sulfhydryl groups.

$\mathrm{S}_{5}, \mathrm{~S}_{12}$ and $\mathrm{S}_{16}: 5,12$ or 16 - doxyl stearic acid spin labels.

Data: median, C.I. $95 \%$ : confidence interval. $(n=6)$.

Degree of significance of the difference between groups: ${ }^{*} p<0.05$

\section{Ex vivo experiments}

Previous analysis [16] performed on erythrocytes from active RA patients (DAS 28-4 > 2,6) showed a good correlation between disease activity and serum HA concentration [HA]s (Pearson product-moment correlation coefficient (r) DAS $28-4$ vs. [HA]s: $0.87, \mathrm{p}<0.0001$ ). Table 3 shows that erythrocytes from the active RA patients have a rigidity index significantly higher than those of the control group, together with a significantly increased [HA]s.

Subsequent correlation analyses were performed between erythrocyte RI and intrinsic and extrinsic parameters. It was found that RI has a significant correlation with [HA]s (r: $0.77 \mathrm{p}<0.00001)$, while it does not correlate either with lipid bilayer rigidity $\left(\mathrm{T}_{/ /}\right)$or with internal viscosity (evaluated through $\mathrm{MCHC}$ ). Also, there was no significant correlation between RI and plasma proteins, namely, $\operatorname{IgG}(\mathrm{r}$ : $0.32, p>0.05)$ and $\operatorname{IgM}(\mathrm{r}: 0.33, \mathrm{p}>0.05$ ), and fibrinogen ( $\mathrm{r}: 0.12, \mathrm{p}>0.05$ ), which might be adsorbed on cell surface modifying the membrane rheology.

\section{Discussion}

Erythrocyte rigidity is a determining factor concerning flow resistance, especially in microcirculation, where RBCs must pass through capillaries of a diameter lower than the cells. Even in macrocirculation, rigidity is a factor of flow resistance, thus contributing to the hiperviscosity syndrome.

HA is a glycosaminoglycan --a high molecular weight polysaccharide--that, similarly to albumin, could interact with the erythrocyte surface. Our hypothesis was that this interaction could lead, in the same way that albumin does, to a reduction in the flexibility of the membrane. The verification of this hypothesis demanded to establish a correlation between RI values and HA medium concentration.

When blood from healthy donors was incubated with several HA concentrations it was corroborated that HA caused a significant decrease in erythrocyte deformability (increase in RI) in a concentration-dependent manner and reversibly- this effect was reverted by washing the treated cells.

In an earlier paper [16] we have demonstrated that RBC's from RA patients presented a considerably increased RI. In the same paper [16] it was corroborated that RI is a reliable indicator for RA activity, given its significant correlation with DAS 28-4 score.

Experiments performed on blood from RA patients in different levels of activity of the disease showed that HA was the only plasma factor that significantly affected deformability; moreover, the expected correlation between RI values and $[\mathrm{HA}] \mathrm{s}$ was found (r: $0.77, \mathrm{p}<0.00001$ ). The discrepancy of RI values in erythrocytes of RA patients

Table 3: Rigidity index and hyaluronic acid concentration in patients with active Rheumatoid Arthritis and their controls

\begin{tabular}{|c|c|c|}
\hline & {$[\mathrm{HA}] \mathrm{s}(\mu \mathrm{g} / \mathrm{ml})$} & RI \\
\hline Controls $(n=40)$ & $20.0 \pm 9.0$ & $7.0 \pm 0.8$ \\
\hline RA Patients ( $n=100)$ & $155.80 \pm 44.0$ & $11.0 \pm 1.3$ \\
\hline$P$ & $<0.00001$ & $<0.001$ \\
\hline
\end{tabular}

[HA]s: serum concentration of hyaluronic acid; RI: rigidity index; RA: rheumatoid arthritis. 
(Table 3) with those of erythrocytes incubated with similar HA levels in the in vitro experiment (Figure 1) should be attributed to the presence in plasma of pathology dependent factors affecting the erythrocyte rheology.

One of the techniques classically employed in RA diagnosis is erythrocyte sedimentation rate (ESR). This value estimates mainly the rise in erythrocyte aggregation. Rouleaux formation depends on medium and cell factors. Consequently, its increase may be explained by the rise in fibrinogen and/or globulin concentration and/or to the modification of the erythrocyte surface properties.

In our in vitro experiments, it was observed that HAtreated RBCs showed a lower aggregation rate (Table 1), i.e., a lower tendency to form rouleaux in comparison to controls. This fact implies that the increased ESR in blood from RA patients could only be attributed to modifications in plasma proteins and not to cell factors [33].

It has been proved that albumin --the smallest and most important plasma protein-- is adsorbed on the erythrocyte surface [13] and, unlike globulins and fibrinogen, hinders the aggregation process. The corroboration that HA presented a similar behaviour to that of albumin constitutes a further support for the claimed hypothesis.

EPR spectroscopy allowed us to investigate the effects caused by the in vitro interaction of HA with RBC membrane. As shown in Table 2, order parameters did not change significantly, indicating that the fluidity of the lipid bilayer was not altered as a consequence of HA incubation. On the contrary, the parameter W/S, calculated from the spectrum of a protein spin label, revealed that HA produces alterations in the spectrin structure of the membrane cytoskeleton increasing the amount of strongly immobilized sites. This result suggests that the increase in erythrocyte rigidity is related to a stiffening of the cytoskeleton. However, as HA only interacts with the outer erythrocyte surface, we postulate that HA interaction results in a protein organizational perturbation that is translated to spectrin in the inner membrane surface.

\section{Conclusions}

Our experiments lead us to accept the hypothesis that HA interacts with the erythrocyte surface, giving place to modifications in erythrocyte rheological and flow properties.

Considering that HA is increased in inflammatory processes and other malignancies, and that it is employed in pharmacologic and cosmetic treatments, in all these cases we claim that the effect of HA upon erythrocytes --and thus on circulatory function-- should not be disregarded; in fact, special attention should be paid to this matter.

\section{Abbreviations}

RA: rheumatoid arthritis; HA: hyaluronic acid; Rl: rigidity index; DAS: Disease Activity Score; HIV: human immunodeficiency virus; EDTA: ethylenediaminetetraacetic acid; ESR: erythrocyte sedimentation rate; $\mathrm{RBC}$ : red blood cell; $\mathrm{PBS}$ : phosphate buffered saline; MCV: mean corpuscular volume; MCHC: mean cor- puscular hæmoglobin concentration; EPR: electron paramagnetic resonance spectroscopy; SH: sulfhydryl groups; [HA]s: serum concentration of hyaluronic acid; $T_{/ / ;}$: nitrogen hyperfine tensor; $S_{5}, S_{12}$ and $S_{16}$ : $E P R$ order parameters determined using 5, 12 or 16-doxyl stearic acid spin labels.

\section{Competing interests}

The authors declare that they have no competing interests.

\section{Authors' contributions}

AL: acquisition, analysis and interpretation of data of haemorheological assays in RA patients and HA purification by ecteola cellulose chromatography. Also involved in drafting the manuscript, revising it critically and in giving final approval of the version to be published. LU: acquisition, analysis and interpretation of data of laboratory assays in RA patients. MJS: Blood sample collection in RA patients and HA assay by an ELISA commercial test kit. AMG: acquisition, analysis and interpretation of data of erythrocyte membrane fluidity estimated by electron paramagnetic resonance spectroscopy (EPR). MEG: acquisition, analysis and interpretation of data of erythrocyte aggregation of the in vitro experiments. GP: acquisition, analysis and interpretation of data of erythrocyte deformability of the in vitro experiments. RV and SP: protocol design and obtention of the consent de RA patients. Determiantion of the clinic activity of the disease, evaluated by means of the Disease Activity Score (DAS 28-4). MR: involved in drafting the manuscript and revising it critically, and giving final approval of the version to be published. All authors read and approved the final manuscript.

\section{Acknowledgements}

We are grateful to Dr. Fumiaki Tacahashi, and Dr. Adriana Dusso for the donation of the ELISA commercial test kit ("CHUGAl" quantitative test Kit). To Dr. Maria del Carmen Fernández and Dr. Digna Caferra for the technical support in the Hyaluronic acid (HA) purification, to Juan Carlos Calvo for his suggestions on the work topic and to M. Eugenia Mangialavori for her collaboration in the translation.

\section{Author Details}

${ }^{1}$ Cátedra de Física Biológica, Facultad de Ciencias Médicas, Universidad Nacional de Rosario, Santa Fe 3100, 2000 Rosario, Argentina, ${ }^{2}$ Sección Inmunidad Celular, Department of Bioquímica Clínica, Universidad Nacional de Rosario, Facultad de Cs. Bioquímicas y Farmacéuticas, Suipacha 531, 2000 Rosario, Argentina, ${ }^{3}$ Facultad de Bioquímica y Ciencias Biológicas, Universidad Nacional del Litoral (UNL) and INTEC (CONICET-UNL), Güemes 3450, 3000 Santa Fe, Argentina and 4 Área Reumatología, Cátedra de Reumatología, Facultad de Ciencias Médicas, Universidad Nacional de Rosario, Santa Fe 3100, 2000

Rosario, Argentina

Received: 10 November 2009 Accepted: 12 February 2010

Published: 12 February 2010

\section{References}

1. Berg S, Brodin B, Hesselvik F, Laurent TC, Maller R: Elevated levels of plasma hyaluronan in septicemia. Scand J Clin Invest 1988, 48:727-32.

2. Cooper EH, Forbes MA: Serum hyaluronic acid levels in cancer. $\mathrm{Br} J$ Cancer 1988, 58:668-669.

3. Engstram-Laurent $A$, Hallgren R: Circulating hyaluronate in rheumatoid arthritis: relationship to inflammatory activity and the effect of corticosteroid therapy. Ann Rheum Dis 1985, 44:83-8.

4. Kovacs IB, Sowemimo-Coker SO, Kirby JDT, Turner P: Altered behaviour of erythrocytes in scleroderma. Clin Sci (Lond) 1983, 65(Suppl 5):515-9.

5. Majeed M, McQueen F, Yeoman S, McLean L: Relationship between serum hyaluronic acid level and disease activity in early rheumatoid arthritis. Ann Rheum Dis 2004, 63:1166-8.

6. Ninomiya T, Yoon S, Hayashi Y, Sugano M, Kumon Y, Seo Y, Shimizu K, Kasuga M: Clinical significance of serum hyaluronic acid as a fibrosis marker in chronic hepatitis $C$ patients treated with interferon- $a$ : Histological evaluation by a modified histological activity index scoring system. J Gastroenterol Hepatol 1998, 13(Suppl 1):68-74.

7. Turan Y, Bal S, Gurgan A, Topac H, Koseoglu M: Serum hyaluronan levels in patients with knee osteoarthritis. Clin Rheum 2007, 26(Suppl 8):1293-1298.

8. Wilkinson CR, Bower LM, Warren C: The relationship between hyaluronidase activity and hyaluronic acid concentration in sera from 
normal controls and from patients with disseminated neoplasm. Clin Chim Acta 1996, 256:165-173.

9. Rosenthal MA, Gibbs P, Brown TJ, Wong S, Uren S, Ellis A, Li L, Heldin P, Fox RM: Fox Phase I and Pharmacokinetic Evaluation of Intravenous Hyaluronic Acid in Combination with Doxorubicin or 5-Fluorouracil. Chemotherapy 2005, 51:132-141.

10. Necas J, Bartosikova L, Brauner P, Kolar J: Hyaluronic acid (hyaluronan): a review. Vet Med 2008, 53(Suppl 8):397-411.

11. Pons-Guiraud A: Hyaluronic Acid: administration \& dosage. Ann Dermatol Venereol 2008, 135(Suppl 1):1527-34.

12. Zhang L, Underhill CB, Chen L: Hyaluronan on the Surface of Tumor Cells Is Correlated with Metastatic Behavior. Cancer Research 1995, 55:428-433.

13. Luquita A, Gennaro AM, Rasia M: Influence of adsorbed plasmatic proteins on erythrocyte rheological properties: in vitro and ex vivo studies. Pflugers Arch 2001, 443:78-83.

14. Baskurt OK, Gelmont D, Meiselman HJ: Red Blood Cell Deformability in Sepsis. Am J Respir Crit Care Med 1998, 157(Suppl 2):421-427.

15. Horii K, Kubo S, Hirohashi K, Kinoshita H: World Changes in Erythrocyte Deformability after Liver Resection for Hepatocellular Carcinoma Associated with Chronic Liver Disease. World J Surg 1999, 23(Suppl 1):85-90.

16. Luquita A, Urli L, Dominighini A, Svetaz MJ, Gennaro AM, R Volpintesta, Palatnik S, Rasia M: Hæmorheological Variables as a Rheumatoid Arthritis activity indicator. Clin Hemorheol Microcir 2004, 30:9-17.

17. The International Response to Helsinki VI - The WMA's Declaration of Helsink on Ethical Principles for Medical Research Involving Human Subjects, as adopted by the 52nd WMA General Assembly, Edinburgh, October 2000

18. Golberg RL: Enzime-linked inmunosorbent assay for hyaluronate using cartilage proteglycan and antybody to keratan sulphate. Analyt Biochem 1988, 174:448-458.

19. Reid HL, Barnes AJ, Lock PJ, Dormandy JA, Dormandy TL: A sample method for measuring erythrocyte deformability. J Clin Pathol 1976, 29:855-8

20. Jones JG, Adams RA, Evans SA: Bulk filtration through micropore membranes for analysing blood cell rheology in clinical research. Clin Hemorheol 1994, 14:149-69.

21. International Committee for Standardization in Haematology: Expert panel on blood rheology. Clin Hemorheol 1986, 6:439-52.

22. Bertoluzzo SM, Bollini A, Rasia M, Raynal A: Kinetic model for erythrocyte aggregation. Blood Cells Mol Dis 1999, 25:338-48.

23. Tomita M, Gotoh F, Tanahashi N, Turcani P: Whole blood red blood cell aggregometer for human and feline blood. Am J Physiol 1986, 251:H1205-10.

24. Brooks DE, Greig RG, Janzen J: Mechanisms of erythrocyte aggregation. In Erythrocyte Mechanics and Blood Flow Edited by: Cokelet GR, Meiselman HJ, Brook DE. New York; Alan R. Liss Inc; 1980:119-40.

25. Campbell ID, Dwek DA: Biological Spectroscopy Menlo Park, CA: Benjamin/ Cummings; 1984

26. Cassera MB, Silber AM, Gennaro AM: Differential effects of cholesterol on acyl chain order in erythrocyte membranes as a function of depth from the surface. An electron paramagnetic resonance (EPR) spin label study. Biophys Chem 2002, 99:117-27.

27. Greiling H, Herbertz T, Stuhlsatz HW: Chromatographische Untersuchungen über die mucopolysaccharidverteilung mi hyalinen Knorpel. Physiol Chem 1964, 336:149-62

28. Greiling H: Hyaluronic acid. In Methods of enzymatic analysis Edited by: Bergmeyer HU. New York: Academic Press; 1974:1158-64.

29. Fung LWM, Johnson M: Multiple motions of the spectrin-actin complex in the saturation transfer EPR time domain. J Magn Reson 1983, 51:233-244

30. Arnett FC, Edworthy SM, Bloch DA, McShane DJ, Fries JF, Cooper NS, Healey LA, Kaplan SR, Liang MH, Luthra HS: The American Rheumatism Association 1987 revised criteria for the classification of rheumatoid arthritis. Arthritis Rheum 1988, 31:315-324.

31. Harrison BJ, Symmons DPM, Barrett EM, Silman AJ: The performance of the 1987 ARA classification criteria for rheumatoid arthritis in a population based cohort of patients with early inflammatory arthritis. J Rheumatol 1998, 25:2324-2330.

32. Van der Heijde DM, Jacobs JW: The original "DAS" and the "DAS28" are not interchangeable. Arthritis Rheum 1998, 41:942-945.
33. Luquita A, Urli L, Svetaz MJ, Gennaro AM, Volpintesta R, Palatnik S, Rasia M: Erythrocyte aggregation in rheumatoid arthritis: cell and plasma factor's role. Clin Hemorheol Microcirc 2009, 41:49-56.

doi: $10.1186 / 1423-0127-17-8$

Cite this article as: Luquita et al., In vitro and ex vivo effect of hyaluronic acid on erythrocyte flow properties Journal of Biomedical Science 2010, 17:8

\section{Submit your next manuscript to BioMed Central and take full advantage of:}

- Convenient online submission

- Thorough peer review

- No space constraints or color figure charges

- Immediate publication on acceptance

- Inclusion in PubMed, CAS, Scopus and Google Scholar

- Research which is freely available for redistribution
C Biomed Central 